\title{
Online disclosure of sexual victimisation: A systematic review
}

\author{
Marleen Gorissen ${ }^{\mathrm{a}}$, Chantal J.W. van den Berg ${ }^{\mathrm{ab}}$, Catrien C.J.H Bijleveld ${ }^{\mathrm{ab}}$, Stijn Ruiter ${ }^{\mathrm{ac}}$, \\ Tamar Berenblum ${ }^{\text {ad } 1}$
}

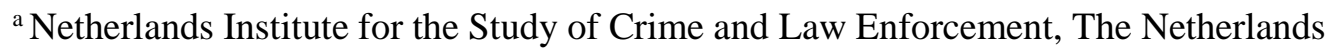

${ }^{\mathrm{b}}$ VU University Amsterdam, The Netherlands

${ }^{\mathrm{c}}$ Utrecht University, the Netherlands

${ }^{\mathrm{d}}$ The Hebrew University of Jerusalem, Israel

This is an Author Accepted Manuscript of an article that has been accepted for publication in Trauma, Violence, \& Abuse. This pre-print is not published under a CC license.

Corresponding author:

Marleen Gorissen, De Boelelaan 1077, 1081 HV Amsterdam, NL

$+31(0) 205985239$

E-mail: MGorissen@nscr.nl

\footnotetext{
${ }^{1}$ The authors wish to thank Liel Shany for her help.
} 


\section{ONLINE DISCLOSURE OF SEXUAL VICTIMISATION}

\section{Abstract}

We map the available scientific literature on how and why victims of sexual violence are using digital platforms in the aftermath of victimisation. Twenty-four empirical studies on sexual victimisation and online disclosure were identified by systematically searching Web of Science and PsycINFO, checking reference lists and consulting authors about relevant publications. The literature on online disclosure of sexual victimisation does not yield a coherent picture. International literature pays limited attention to the various components of online disclosure like the characteristics of victims who disclosure online and the characteristics of the disclosure messages. Most studies focused on motivations for and reactions to online disclosure. Victims of sexual violence disclose sexual victimisation online to seek support, for clarification and validation, unburdening, documenting, seeking justice, informing others or commercial goals (individual-oriented disclosure) and to provide support, educate and as a form of activism (other-oriented disclosure). Responses to online disclosure are predominantly positive, containing advocacy and support. Negative responses are rare. This review provides a comprehensive overview of multidisciplinary empirical information and displays knowledge gaps in victimological research. Future research should use a robust quantitative and/or qualitative design with a substantial sample size, comparing victims who do disclose their sexual victimisation online with victims who do not, and compare disclosure on different online platforms to increase generalisability of the results. Potential for online informal support is identified, in which online disclosure can serve as a relatively safe alternative to offline disclosure. This offers important points of intervention for assistance and victim support by social workers in facilitating the use of the internet for support for victims of sexual violence.

Keywords: sexual victimisation, sexual assault, sexual abuse, victim/survivor, online disclosure, social media, viral justice 


\section{ONLINE DISCLOSURE OF SEXUAL VICTIMISATION}

\section{Online disclosure of sexual victimisation: A systematic review}

In the international victimological literature, the telling of a story of victimisation is referred to as 'disclosure'. A study by London, Bruck, Wright and Ceci (2008) found that many victims of child sexual abuse wait years to disclose their experiences or even never report the abuse. ${ }^{1}$ Victims of sexual violence experience additional obstacles compared to victims of other crimes since sexual victimisation has traditionally not been a socially accepted issue for disclosure (Carretta, Burgess \& DeMarcos, 2016). Sexual violence is a highly stigmatised experience (Kennedy \& Prock, 2018) and no other group of victims is blamed for their experiences as victims of sexual violence are (Bhuptani \& Messman-Moore, 2019). Stigma arises from societal beliefs and rape myths consisting of "prejudicial, stereotyped, or false beliefs about rape, rape victims, and rapists" (Burt, 1980, p. 217) where sexual violence was, and sometimes still is, seen as something victims themselves are to blame for. To prevent social stigma from disclosure of sexual violence, many victims try to avoid conflict and confrontation by remaining silent about what has happened to them (Carretta et al., 2016; Edwards, Turchik, Dardis, Reynolds, \& Gidycz, 2011). International research shows that rates of nondisclosure among victims of sexual violence range from 19 percent to 48 percent (Ahrens, Rios-Mandel, Isas \& del Carmen Lopez, 2010; Carretta et al., 2016; Carson, Babad, Brown, Brumbaugh, Castillo \& Nikulina, 2019; Hébert, Tourigny, Cyr, McDuff \& Joly, 2009; Jacques-Tiura, Tkatch, Abbey \& Wegner, 2010; Ullman, 2011). Feelings of shame, guilt, self-blame, fear of not being believed, fear of negative social reactions, not recognizing the event as a crime and not wanting to involve the police are mentioned as the most important barriers to disclose (Carretta et al., 2016; Sable, Danis, Mauzy \& Gallagher, 2006; Starzynski, Ullman, Filipas, \& Townsend, 2005; Thompson, Sitterle, Clay \& Kingree, 2007; Ullman, O’Callaghan, Shepp \& Harris, 2020; Zinzow \& Thompson, 2011).

Non-disclosure can however have negative long-term consequences for the 
ONLINE DISCLOSURE OF SEXUAL VICTIMISATION

(psychological) health of victims (Ahrens et al., 2010; Sinclair \& Gold, 1997). The sharing of experiences of sexual victimisation is associated with improved psychological and mental health due to the cognitive and emotional processing of the trauma (Pennebaker, Zech \& Rime, 2001; Rime, 1995). The simple act of writing the incident down often has a cathartic effect and helps the victim to be able to better understand their emotional and traumatic experience(s) (Pennebaker \& Seagal, 1999; Pennebaker, 1997; Suler, 2004).

That does not mean that disclosure is always beneficial for the mental health of victims. Whether or not disclosure is salutary depends on the nature of the responses to disclosure someone receives (Ahrens et al., 2010; Ullman, 2011). Victims are sensitive to feedback and the responses of the first people with whom the incident was shared often determine the willingness to continue to talk about it (Sudderth, 1998). Responses can be positive (e.g., expressing validation and belief, emotional support, tangible aid) or negative (e.g., disbelief, blaming the victim) (Ullman, 2000). Research shows that victims weigh anticipated or imagined reactions to disclosure in a risk assessment process determining if, how, when, where and what to disclose and considering the degree of vulnerability affiliated with disclosure (Petronio, 2002). Negative reactions to disclosure of victimisation can be harmful to victims and may even result in prolonged and worsened consequences of the experience (also known as secondary victimisation; Williams, 1984) as a result of, among other things, judgemental attitudes, a lack of support and victim blaming (Nagy, 2016; Powell, 2015; Thompson, Wood \& Rose, 2016). Ahrens, Campbell, Ternier-Thames, Wasco and Sefl (2007) found that victim blaming responses to disclosure of sexual victimisation strengthened feelings of shame and impeded further disclosure. On the other hand, positive responses like support or validation are associated with enhanced self-worth and lower levels of psychological suffering (Orchowski \& Gidycz, 2015; Orchowski, Untied \& Gidycz, 2013).

In addition to traditional ways of disclosure of sexual victimisation, online sharing of 


\section{ONLINE DISCLOSURE OF SEXUAL VICTIMISATION}

such negative experiences is on the rise. The internet and social media are becoming more and more part and parcel of everyday life, with a growing number of people having access to the digital world. This in turn also changes the way people interact and communicate with each other (Hinduja \& Patchin, 2008). The increased possibilities for online disclosure, the sharing of personal experiences of sexual victimisation or implicit disclosure of victimisation using communication technology like mobile phones, tablets, computers, and other devices connected to the internet (Powell, 2015), may influence the cost-benefit analysis victims make before they disclose their experiences. It is assumed that, due to its anonymity and accessibility, the internet could disinhibit users in sharing personal and intimate experiences (Smith, 2010) and might counter the offline prevailing stigma and shame causing high non-disclosure of sexual victimisation. Suler (2004) describes this phenomenon in his online disinhibition theory. According to Suler (2004) the internet can have an inhibitory effect on someone's (behavioural) constraints. In other words, properties of the internet can lead to the removal of (psychological) barriers and restraints that block the disclosure of sexual victimisation in the offline world. This disinhibition may lead to victims of sexual violence opting for online disclosure more often compared to offline disclosure (Smith, 2010).

The possibility to remain anonymous online also applies to people who read and respond to online disclosure messages. They too can choose to keep their identity hidden and say or do things they would normally not say or do in the offline world. People feel less inhibited in online social contact, act looser and more openly express (personal) information because they are less concerned with the opinions of others and how to present themselves (Suler, 2004; Joinson, 1998). This may, due to the absence of expectations to behave in a socially desirable manner, result in more negative responses to online disclosure of sexual victimisation.

However, little research has been done on the disclosure of sensitive topics in an online environment and the reactions to these disclosure posts. Even less is known about online 
ONLINE DISCLOSURE OF SEXUAL VICTIMISATION

disclosure of sexual victimisation. As mentioned earlier, victims experience serious negative consequences of sexual victimisation like depression and suicidal thoughts (Dworkin, Menon, Bystrynski \& Allen, 2017), stigma, shame and victim blaming are eminently common (Bhuptani \& Messman-Moore, 2019; Kennedy \& Prock, 2018) and disclosure and reporting rates of sexual victimisation are low (e.g. Carson et al., 2019). The internet might offer an alternative. A better understanding of the motives of victims to share their stories in an online setting can help design policies and resources that match the needs of victims of sexual violence. Reactions to online disclosure are expected to have an impact on the victim's (mental) health and their future decisions to disclose. Insight into the nature and effects of online responses to online disclosures can have implications for assistance in support and counselling of victims. This understanding can help prevention of (online) victimisation in cases of negative responses or retributive violence following online disclosure (Powell, 2015; Thompson et al., 2016).

This article reports on findings of a systematic literature review of studies on online disclosure of sexual victimisation and sheds light on the motivations and choices of victims who disclose their experiences online. In addition, it aims to identify the effect of and responses to online disclosure of sexual violence. The central research questions are: 'Which motivations play a role for victims of sexual violence in the online disclosure of their victimisation?' and 'What reactions do victims of sexual violence receive on online disclosure of sexual victimisation?'. To answer these questions several sub-questions are important.

1. What are the characteristics of victims of sexual violence who disclose their story online?

2. What are the characteristics of the online disclosure messages of sexual violence?

3. What reasons do victims of sexual violence give for their online disclosure?

4. What is the effect of online disclosure of sexual violence on victims? 
ONLINE DISCLOSURE OF SEXUAL VICTIMISATION

5. What are the characteristics of the responses to online disclosure of sexual victimisation?

6. What is the effect of the responses to online disclosure on victims of sexual violence?

The motivations to disclose sexual violence (why) speak to the goal and aim of disclosing and additionally touch on the audience (whom), where to disclose what and how, and the timing of disclosure (when). In this review attention will be paid to how the empirical studies answer these questions, what methods were used to answer these questions and the strength of the evidence provided in the studies.

\section{Methods}

\section{Search Strategy}

In the period from December 3 to December 19, 2018, the Internet databases Web of Science and PsycINFO were searched. Given the timeliness of the subject and several viral hashtag movements (\#NotOkay, October 2016; \#MeToo, October 2017; \#WhyIDidntReport, September 2018), the literature study was further supplemented with the most recent publications in a second literature search in the period from 3 December 2019 to 19 February 2020. Both the first and second searches included the same search terms. Additional to searching the two databases, reference lists were checked. All articles were included for screening and assessment of eligibility. The screening and assessment were based on a protocol that was developed in consultation with all authors.

Several search terms and combinations of search terms were used to collect relevant studies. Search terms were based on keywords such as 'disclos*', and 'self-report' combined with search terms related to sexual victimisation ('sex* assault', 'sex* abuse', 'sex* harass*', 'sex* intimidat*' 'sex* victim*', 'sex* survivor*') and keywords related to the internet ('internet', 'cyber', 'online', 'social media'). A first exploration of the search results showed that some of the studies on online disclosure reported from an ideological or activist point of 


\section{ONLINE DISCLOSURE OF SEXUAL VICTIMISATION}

view. Furthermore, several hashtags associated with online disclosure (e.g., \#whyididntreport or \#MeToo) are driven by activist principles. To identify all relevant publications, the literature search was extended with search terms related to the online sharing of sexual victimisation to pursue activist goals. The keywords related to sexual victimisation and the internet were combined with the words 'justice', 'activism' and 'protest' and 'informal justice'. Finally, a search was done with the individual search terms 'viral justice', 'e-shaming', 'online shaming', 'me too' and '\#MeToo'. Due to the Dutch nationality and native language of the majority of the authors, the search was expanded with Dutch translations of the aforementioned English keywords. ${ }^{2}$ No additional studies were found.

As part of the protocol of a systematic literature review, authors of identified literature on online disclosure of sexual victimisation were approached. A total of 79 authors were emailed and asked to mention possible additional publications. This resulted in no new publications for review. Finally, one of the authors of this systematic review is of Israeli nationality and identified three more Hebrew articles that met the inclusion criteria. These three studies have therefore been added to the review in addition to the systematic search.

\section{Inclusion and Exclusion Criteria}

Studies were only included if they met the pre-established inclusion criteria. It had to be (a) English, or Dutch-language publications, (b) empirical (qualitative or quantitative) studies, (c) accessible via Web of Science and PsycINFO. Dissertations and other publications were included. Importantly, studies had to deal with (d) victims of sexual violence and (e) online disclosure of these victims or responses to online disclosure of sexual victimisation. The word 'sexual violence' is used as an umbrella term to include a wide array of experiences from (attempted) rape to sexual harassment. Studies on gender discrimination or sexism, online disclosure of experiences of sexual victimisation by someone other than the author of the online 
ONLINE DISCLOSURE OF SEXUAL VICTIMISATION

post, social reactions to general messages (non-disclosure of victimisation) about sexual violence, case studies, essays and literature reviews were excluded.

\section{Study Selection}

The literature search identified 3,768 articles, including duplicates, case studies, non-English, non-Dutch or non-Hebrew articles. After screening the titles and abstracts, 94 articles were identified and retrieved for full-text review. The assessment resulted in 68 articles being excluded because they were either non-empirical $(N=10)$, did not meet the inclusion criteria $(N$ $=56)$ or the full text could not be accessed $(N=2)$. Finally, 26 articles met the inclusion criteria and were included in the systematic review. Since three articles used the same data, the studies were merged, resulting in a review of 24 studies (see Flowchart). The screening and assessment were performed by the first author.

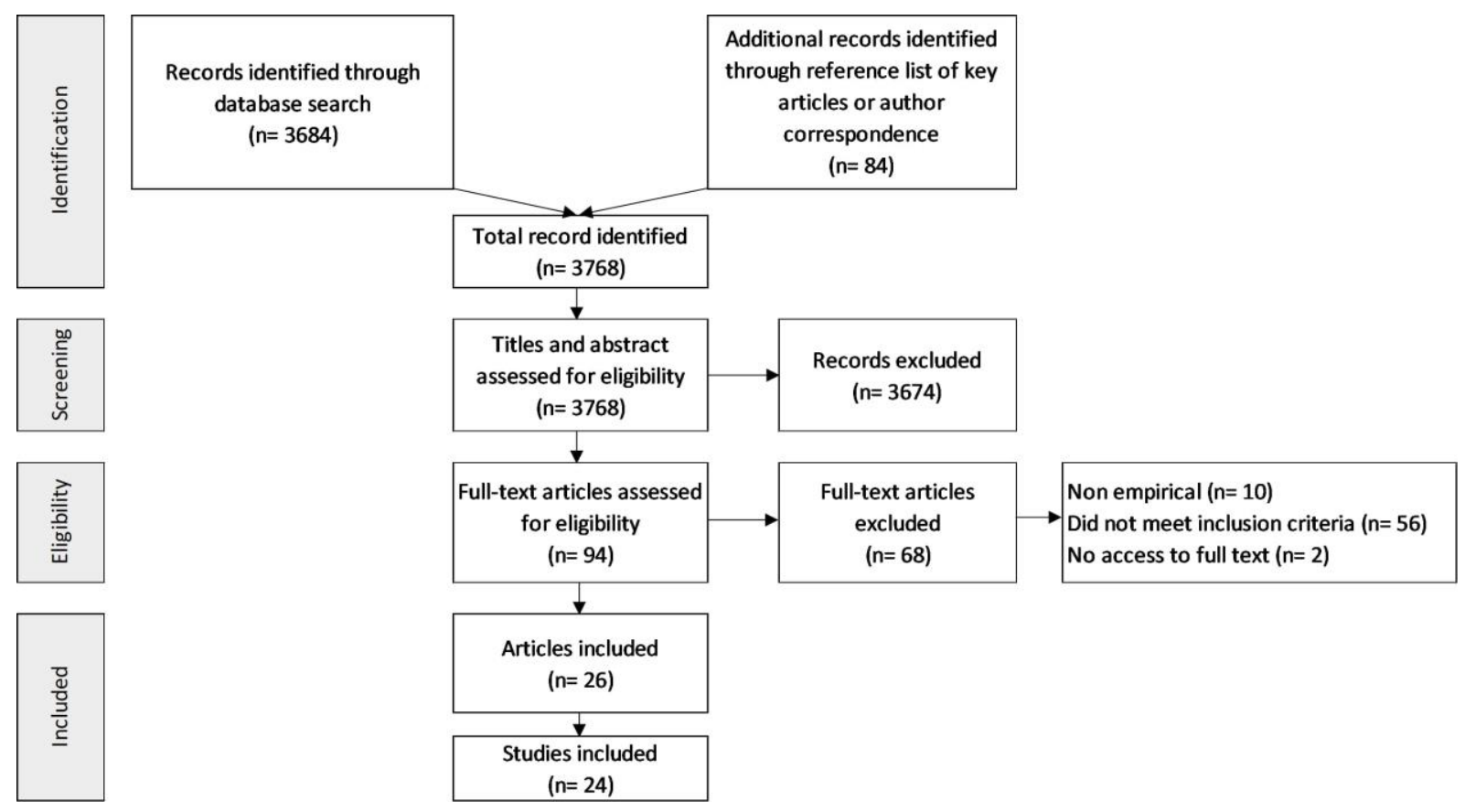

Information was extracted on authors and year published, the study design (quantitative, qualitative or mixed methods), methods of data collection, reference period, study site, research questions, theoretical framework and key findings. 
ONLINE DISCLOSURE OF SEXUAL VICTIMISATION

\section{Results}

\section{Characteristics of Included Studies}

The majority of the included articles $(N=21)$ were published and peer-reviewed. The review also contains a dissertation (Barta, 2019), a publication in proceedings of a conference (Andalibi, Haimson, De Choudury \& Forte, 2016), a preprint (Masciantonio, Schumann \& Bourguignon, 2020) and two publications of which it is unknown whether they were peerreviewed (Andalibi, Haimson, De Choudury \& Forte, 2018; Webber \& Wilmot, 2012).

About half of the articles $(N=10)$ contained an explicitly formulated research question (Andalibi et al., 2016; Andalibi et al., 2018; Bogen, Bleiweiss, \& Orchowski, 2018a; Barta, 2019; Fileborn, 2017; Loney-Howes, 2018; Lowenstein-Barkai, 2020; Masciantonio et al., 2020; Mendes, Keller \& Ringrose, 2019; Schneider \& Carpenter, 2020). The various research questions were aimed at answering questions about what victims of sexual violence share online (Andalibi et al., 2016; Mendes et al., 2019), what motivations and goals victims have to share their story online (Barta, 2019; Masciantonio et al., 2020) and what kind of responses online disclosures of sexual victimisation elicit (Andalibi et al., 2018; Barta, 2019; Bogen et al., 2018a). Furthermore, online disclosure and responses to online disclosure were considered in relation to social support (Andalibi et al., 2016, Andalibi et al., 2018; Barta, 2019; LowensteinBarkai, 2020), coping (Barta, 2019; Schneider \& Carpenter, 2020), visibility (Andalibi et al., 2016; Andalibi et al., 2018; Barta, 2019) and activist goals (Fileborn, 2017; Loney-Howes, 2018). The other studies merely mentioned the aim of the research instead of formulating a specific research question. One study had a formulated hypothesis but did not articulate a research question to test the hypothesis (Bogen, Bleiweiss, Leach \& Orchowski, 2019). A few studies used theories to explain, predict or understand the results. The used theoretical frameworks can be found in the supplementary file.

The year of publication of the included studies ranged from 2012 (Moors \& Webber, 2012; Webber \& Wilmot, 2012) to 2020 (Dancig-Rosenberg \& Peleg, 2020a, 2020b, 2020c; 
ONLINE DISCLOSURE OF SEXUAL VICTIMISATION

Gundersen \& Zaleski, 2020; Lowenstein-Barkai, 2020; Masciantonio et al., 2020; Schneider \& Carpenter, 2020). The year 2018 was the period with most publications on online disclosure of sexual victimisation $(N=7)$, followed by $2019(N=5)$. This illustrates the recency of the subject and the research in this field.

The majority of the included studies $(N=19,83 \%)$ are from English-speaking countries and focus on English online disclosure posts. One study focusses on a specific hashtag movement in Ukraine and Russia. The remaining studies are from Brazil, France and Israel.

The studies were largely qualitative in nature $(N=15)$. Two studies were quantitative (Lowenstein-Barkai, 2020; Modrek \& Chakalov, 2019) and seven used mixed methods (Andalibi et al., 2016; Andalibi et al., 2018; Dancig-Rosenberg \& Peleg, 2020a, 2020b, 2020c; Fileborn, 2017; Lokot, 2018; Loney-Howes, 2018; Schneider \& Carpenter, 2020).

Most of the included studies $(N=19)$ conducted a content analysis of online messages. In four studies victims were interviewed (Barta, 2019; Dancig-Rosenberg \& Peleg, 2020a, 2020b, 2020c; Gundersen \& Zaleski, 2020; Loney-Howes, 2018), of which one study combined both a content analysis with interviews (Loney-Howes, 2018). Finally, two studies consisted of a survey (Dancig-Rosenberg \& Peleg, 2020b; Masciantonio et al., 2020) and one study used a survey design and a focus group (Fileborn, 2017).

A part of the included articles studied a specific hashtag or an online movement $(N=$ 10), usually aimed at raising awareness and social change. The \#MeToo movement was studied in six articles (Bogen et al., 2019; Dancig-Rosenberg \& Peleg, 2020b, 2020c; LowensteinBarkai, 2020; Modrek \& Chakalov, 2019; Schneider \& Carpenter, 2020), varying from studying the first 24 hours after the first \#MeToo post (Schneider \& Carpenter, 2020), to the first week (Bogen et al., 2019; Modrek \& Chakalov, 2019) or first three weeks of the movement (Lowenstein-Barkai, 2020). Other studies also focused on specific hashtags such as the hashtags \#NotOkay (Bogen, Millman, Huntington \& Orchowski, 2018b; Bogen et al., 2018a), 
ONLINE DISCLOSURE OF SEXUAL VICTIMISATION

\#BeenRapedNeverReported (Mendes et al., 2019), \#WhyIDidntReport (Lowenstein-Barkai, 2020), \#ЯНеБоюсьСказати, Ukrainian for \#IAmNotAfraidToSayIt (Lokot, 2018), \#primeiroassedio (Fornari, Sakata-So, Egry \& da Fonseca, 2018) and 'my rape story' videos (Harrington, 2019).

The articles looked at online disclosure on various platforms. Twitter was researched most often in nine of the twenty-four articles, followed by Reddit (Andalibi et al., 2016; Andalibi et al., 2018; O’Neill, 2018) and Yahoo! Answers (Moors \& Webber, 2012; Webber \& Moors, 2015; Webber, 2014). Furthermore, the platforms Facebook (Dancig-Rosenberg \& Peleg, 2020a, 2020b, 2020c; Lokot, 2018; Lowenstein-Barkai, 2020), YouTube (Harrington, 2019), Tumblr (Mendes et al., 2019), Somazone (Webber \& Wilmot, 2012) and blogs (Fawcett \& Shrestha, 2016) were the object of analysis.

\section{Characteristics of Disclosers}

Only five studies (Andalibi et al., 2016; Lokot, 2018; Masciantonio et al., 2020; Modrek \& Chakalov, 2019; Webber \& Wilmot, 2012) looked at characteristics of victims who share their stories in an online environment. In the vast majority of the studies the characteristics of online disclosers remain unexplored. One article studied the gender of the discloser by classifying the victim's username as either male or female using the Ukrainian State Census list of names (Lokot, 2018). Another quantitative study used a commercial prediction service to infer demographic information of disclosers (Modrek \& Chakalov, 2019). All found that it is mostly women who disclose sexual victimisation online. Furthermore, Modrek and Chakalov (2019) indicate that in online disclosure practices white women and users aged 25 to 50 years old are overrepresented. The results should be interpreted with caution, because both methods to deduce demographic information were not specified or exemplified and the used algorithms remain covert. The quality of the classification is therefore unknown.

One study conducted a survey and compared a group of victims of sexual violence who 
ONLINE DISCLOSURE OF SEXUAL VICTIMISATION

shared their experiences on Twitter with a group of victims who did not (Masciantonio et al., 2020). They found that the mean age of victims who share their story online is 31.8 compared to a mean age of 26.7 of victims who do not.

\section{Characteristics of Disclosure Messages}

In this section the characteristics of online disclosure messages of sexual victimisation are discussed. Attention will be paid to how the incidents were labelled, what is mentioned about why victimisation occurred, the tone of the disclosure messages, what is disclosed (impact of the experience and perpetrator information), how victimisation and online disclosure occurred, when victimisation and online disclosure occurred and where victimisation and online disclosure occurred.

Labelling incident. Eight qualitative, quantitative as well as mixed method studies reported on how victims labelled the incident in the disclosure messages (Bogen et al., 2018b; Bogen et al., 2019; Harrington, 2019; Lokot, 2018; Mendes et al., 2019; Modrek \& Chakalov, 2019; Schneider \& Carpenter, 2020; Webber \& Wilmot, 2012). The degree of detail in which victims describe their experience differs greatly between studies. In most cases no information was available on the type of victimisation (Mendes et al., 2019; Schneider \& Carpenter, 2020). Words like "rape" and "sexual assault" were often absent (Mendes et al., 2019). Modrek and Chakalov (2019) used machine learning methods to create an archetype of online disclosures of sexual victimisation. They found that the words "grope", "drunk", "asleep", "afraid", but also "rape", were the most predictive of disclosure tweets. Some victims gave detailed descriptions of their experiences, including a description of the events leading up to the experience. Other victims shared their experiences in abstract terms (Lokot, 2018; Harrington, 2019). While one study found that $73 \%$ of victims explicitly described the type of violence (Bogen et al., 2018b), other studies found only $24 \%$ (Bogen et al., 2019) or stated that victims rarely labelled the incident. 
ONLINE DISCLOSURE OF SEXUAL VICTIMISATION

Why victimisation occurred. Two qualitative studies concluded that some victims rationalised in their disclosure why they believed the victimisation had occurred (Bogen et al., 2018b; Bogen et al., 2019). Content analysis revealed that only a small proportion of the victims provide such explanations for why it happened, namely between 2\% (Bogen et al., 2019) and 11\% (Bogen et al., 2018b). The motivations for why victims share their story are discussed in the next section.

Tone of disclosure messages. The tone of the messages and emotions of the disclosures are mentioned in six studies (Andalibi et al., 2016; Bogen et al., 2018b; Lokot, 2018; Masciantonio et al., 2020; Mendes et al., 2019; Moors \& Webber, 2012). These studies were mainly qualitative in nature or mixed methods (Andalibi et al., 2016; Lokot, 2018). Disclosures of sexual victimisation contain a broad range of emotions. Shame was mentioned as a prevailing sentiment in four studies (Andalibi et al., 2016; Lokot, 2018; Masciantonio et al., 2020; Moors \& Webber, 2012). Lokot (2018) mentioned the emotion shame in the context of being ashamed of the story becoming public and scored this as a separate emotion from shame in general. The emotion sadness appeared in $55 \%$ of the Reddit posts about sexual abuse in the study of Andalibi and colleagues (2016). This emotion was also mentioned in other studies (Bogen et al., 2018b; Lokot, 2018). Further emotions that emerge in online disclosures of sexual victimisation are fear (Andalibi et al., 2016; Bogen et al., 2018b; Moors \& Webber, 2012), fear of possible reoccurrence (Lokot, 2018), anger (Andalibi et al., 2016; Bogen et al., 2018b; Mendes et al., 2019), neglect (Andalibi et al., 2016), resentment (Mendes et al., 2019), loneliness (Moors \& Webber, 2012), confusion (Moors \& Webber, 2012), self-blame (Bogen et al., 2018b) and feelings of going mad (Moors \& Webber, 2012).

How emotions in the online disclosure were classified remains unclear for most of the studies. Mendes and colleagues (2019) state that emotions were conveyed via the use of capitalization, bolding, underlining, the use of exclamation marks or highlighting of keywords. 
ONLINE DISCLOSURE OF SEXUAL VICTIMISATION

Other studies did not indicate how emotions or tone of online disclosures were operationalised.

Impact of victimisation. Eight studies described that disclosure messages often contained a description of the aftermath and social and psychological effects of sexual victimisation on the everyday lives of the victim (Andalibi et al., 2016; Bogen et al., 2018b; Fawcett \& Shrestha, 2016; Fornari et al., 2018; Harrington, 2019; Lokot, 2018; Mendes et al., 2019; Webber, 2014). Disclosures often contained detailed accounts of distress, thoughts and fears, traumas and mental health problems like post-traumatic stress disorder, anxiety, depression and self-mutilation. Two studies reported on the prevalence of describing the impact of victimisation, namely between 33\% (Bogen et al., 2018b) and 58\% (Andalibi et al., 2016).

Perpetrator information. Nine studies documented that victims shared information about the identity of the perpetrator (Barta, 2019; Bogen et al., 2018b; Bogen et al., 2019; Dancig-Rosenberg \& Peleg, 2020c; Fornari et al., 2018; Harrington, 2019; Lokot, 2018; Schneider \& Carpenter, 2020; Webber \& Wilmot, 2012). Information about the perpetrator varied from mentioning the relationship of the victim to the perpetrator, to naming the perpetrator or the organization where the assault took place. Schneider and Carpenter (2020) found that $2.3 \%$ of the victims mentioned the perpetrator in their online disclosure. Furthermore, Bogen and colleagues (2019) found that $20 \%$ of the victims shared details about the perpetrator online and $18 \%$ revealed the sex of the perpetrator.

About half of the participants in the study of Dancig-Rosenberg and Peleg (2020c) shamed their perpetrator online. They did so to warn others against the perpetrator, to assist investigative authorities in the collection of evidence, for the public's right to information, to change power relation imbalances, as social punishment, to provide a voice to those who have been silenced and to encourage victims' support. The effects of disclosing the perpetrator were either positive in the form of personal relief, or negative like online defamation, negative offline responses, the perpetrator was perceived as a victim, the due process principle was violated and 
ONLINE DISCLOSURE OF SEXUAL VICTIMISATION

the online shaming unleashed a puritanical discourse (Dancig-Rosenberg \& Peleg, 2020c). The participants who did not share information about the perpetrator refrained from doing this because it is diverting the feminist fight from its true objectives or out of fear (for both physical or legal consequences) or out of mercy for the perpetrator (Dancig-Rosenberg \& Peleg, 2020c).

How victimisation occurred. Two studies have documented whether the disclosures address how the incident occurred and described perpetrator tactics. Bogen and colleagues (2019) found that $22 \%$ of online posts pay attention to how it happened compared to the $34 \%$ found in the study by Bogen and colleagues (2018b).

How online disclosure occurred. With regard to how victimisation was shared online, two studies provided answers (Harrington, 2019; Mendes et al., 2019). Harrington (2019) found that victims on YouTube had two formats to share their story: using cue cards or by speaking to the camera. Furthermore, a small part of the victims shared their experience under a pseudonym and hid their faces. In contrast, Mendes and colleagues (2019) found that only 14\% of the victims had their faces visible, indicating a higher proportion of anonymous disclosures.

When victimisation occurred. In eleven studies, statements were made about the timing of the incident (Barta, 2019; Bogen et al., 2018b; Bogen et al., 2019; Fornari et al., 2018; Lokot, 2018; Modrek \& Chakalov, 2019; Mendes et al., 2019; Moors \& Webber, 2012; Schneider \& Carpenter, 2020; Webber, 2014; Webber \& Wilmot, 2012). These studies were both qualitative and quantitative (Modrek \& Chakalov, 2019). The primary way of representing the time of victimisation was by reporting the age of the victim at the time of the incident (Bogen et al., 2018b; Bogen et al., 2019; Fornari et al., 2018; Mendes et al., 2019; Modrek \& Chakalov, 2019). Other indications of timing were how long ago the victimisation took place and the year in which it happened. The vast majority of studies only reported how often the temporal information appeared in disclosure messages instead of reporting on actual age at victimisation. Between 9\% (Schneider \& Carpenter, 2020) and 55\% (Bogen et al., 2018b) of 


\section{ONLINE DISCLOSURE OF SEXUAL VICTIMISATION}

the online disclosures contain information about when the victimisation had taken place.

When online disclosure occurred. Statements on the timing of the online disclosure of sexual victimisation were made in four studies (Barta, 2019; Moors \& Webber, 2012; Lokot, 2018; Webber, 2014) Moors and Webber (2012) found that most victims recounted that the incident occurred more than two years ago, followed by a group of victims who disclosed an experience that took place up to two years ago. Only a small proportion of the victims disclosed recent experiences or ongoing victimisation online (Moors \& Webber, 2012). Bartas (2019) findings are in line with the conclusions of the aforementioned researchers. She stated that victims delayed online disclosure until they reached the point in their recovery in which they felt prepared and confident to talk about the sexual victimisation. Also, victims sometimes become motivated to share their own story by reading stories of others who have shared their victim experience online (Lokot, 2018). Finally, Moors and Webber (2012), Webber and Wilmot (2012) and Webber (2014) found that over half of the victims who disclosed their experience online had never shared their story before. For some, online disclosure might be seen as an alternative to offline forms of sharing sexual victimisation. Studies described feelings of having 'nowhere else to turn to' (Moors \& Webber, 2012) or dissatisfaction with previous offline disclosure (Andalibi et al., 2016; Barta, 2019; Fawcett \& Shrestha, 2016; Fornari et al., 2018; O’Neill, 2018) spurring online disclosure.

Where victimisation occurred. The extent to which the online messages pay attention to where (the location) the incidents took place is limited. Four of the 24 included studies comprised information about the locations of the sexual victimisation (Bogen et al., 2018b; Bogen et al., 2019; Fornari et al., 2018; Schneider and Carpenter, 2020). Fornari and colleagues (2018) reported that in almost half of the online disclosures of sexual victimisation (48\%) the location of the sexual violence was reported to be at the home of the victim, followed by victimisation out on the streets (14\%). Schneider and Carpenter (2020) on the other hand found 


\section{ONLINE DISCLOSURE OF SEXUAL VICTIMISATION}

that the majority of the experiences of sexual victimisation occurred at work (32\%). The percentages of whether a location was mentioned vary widely. For example, Bogen and colleagues (2019) found that $11 \%$ of the tweets with the hashtag \#MeToo contained information about where the sexual violence occurred, versus $42 \%$ of the tweets with the hashtag \#NotOkay (Bogen et al., 2018b).

Where online disclosure occurred. A single study (Barta, 2019) focused on where the story was shared (platform choice). Barta (2019) concluded that victims used different platforms to disclose their story for different uses. Platform choice is also dependent on the target audience. She found that victims use Facebook more often to disclose to friends and family, whereas Twitter is mostly used for unknown and professional connections.

\section{Motivations for Online Disclosure of Sexual Victimisation}

In 15 of the 24 included studies, statements were made about the motivations victims of sexual violence have to share their story online. Qualitative and mixed methods studies provided insights into these motivations. Concerning the question for whom victims share their story only one study provided answers. Based on 27 interviews, Barta (2019) concluded that selfdeclared victims of sexual violence may have different target audiences when disclosing online. These target audiences are the self, friends, family, other victims and others. The different target audiences translate into different motivations for online disclosure. A distinction can be made between motivations for victims themselves (individual-oriented disclosure) and disclosure aimed at others (other-oriented disclosure). Crocker, Garcia and Nuer (2008) describe the perspective of the individual-oriented (Crocker et al. call this egosystem oriented) as selfbenefiting, compared to the other-benefiting perspective of the other-oriented (referred to as ecosystem oriented). Although a distinction between self-focused and other-focused motivations is helpful, it is not always possible to draw a clear divide between self- or other- 
ONLINE DISCLOSURE OF SEXUAL VICTIMISATION

focused motivations since motives can be twofold. In this review the division is used to categorise a wide range of motivations found in the different studies.

\section{Individual-orientated Disclosure}

Seek support. First, victims share their story online to seek support, help and advice. This includes emotional and psychological support, advice on how to cope with the experience and information about practical issues (O’Neill, 2018; Webber, 2014; Webber \& Wilmot, 2012). This motivation was found in eight studies (Andalibi et al., 2016; Barta, 2019; DancigRosenberg \& Peleg, 2020a; Fawcett \& Shrestha, 2016; Moors \& Webber, 2012; O’Neill, 2018; Webber, 2014; Webber \& Wilmot, 2012).

Clarification and validation. The need for help and support is also related to the need to interpret, clarify, label and validate the experience. Stories of sexual victimisation are shared for knowledge acquisition and to find clarification and validation on how an experience should be interpreted (Dancig-Rosenberg \& Peleg, 2020a; Webber, 2014). Readers of the disclosure can be asked to provide some sort of second opinion. Online disclosure can also be used to claim recognition of victimisation (Loney-Howes, 2018). This motivation for online disclosure was documented in seven studies (Dancig-Rosenberg \& Peleg, 2020a; Fawcett \& Shrestha, 2016; Fileborn, 2017; Loney-Howes, 2018; Moors \& Webber, 2012; Webber, 2014; Webber \& Wilmot, 2012).

Unburdening. Victims of sexual violence also disclose their story online as a way of emotional release and catharsis. This process is also known as "unburdening" and entails the release of emotions and feelings of shame and self-blame as a form of confessional writing (Moors \& Webber, 2012). Barta (2019) describes this as feeling a need to release the story from the body to someone else. This motivation to disclose was reported in five studies (Barta, 2019; Dancig-Rosenberg \& Peleg, 2020a; Fileborn, 2017; Gundersen \& Zaleski, 2020; Moors \& Webber, 2012). 


\section{ONLINE DISCLOSURE OF SEXUAL VICTIMISATION}

Documenting. The fourth motivation for online disclosure of sexual victimisation is the need to document the experience. Online disclosure is used as a way to provide testimony (O’Neill, 2018) and document personal achievements and recovery (Fawcett \& Shrestha, 2016; Barta, 2019; Fileborn, 2017). This way disclosing can mark a point of recovery where the victim can look back and see personal growth (Fileborn, 2017). Online disclosure can also be interpreted as a way of regaining control over the story by having the ability to decide when and where the story is shared (Barta, 2019; Dancig-Rosenberg, 2020a; O’Neill, 2018). Documenting as a motivation for online disclosure was found in six studies (Barta, 2019; Dancig-Rosenberg \& Peleg, 2020a; Fileborn, 2017; Fawcett \& Shrestha, 2016; Harrington, 2019; O’Neill, 2018).

Seeking justice. The motivation to seek justice can be classified as the fifth motivation for online disclosure of sexual victimisation. The victim and his or her needs for justice are central to this motivation. By sharing the story online and addressing perpetrators directly or indirectly, victims try to achieve personal empowerment and hold perpetrators responsible. For some victims, sharing their experience online and being heard, taken seriously and being acknowledged is a first step in working towards gaining a form of justice (Fileborn, 2017). This motivation was found in four studies (Barta, 2019; Dancig-Rosenberg \& Peleg, 2020a; Fileborn, 2017; Lokot, 2018).

Informing others. Barta (2019) found that victims are also motivated to share their sexual victimisation online to inform and update others about their recovery. Informing and updating others is a way of clarifying one's behaviour to others and differs from the effort to reclaim one's story or voice. The underlying motivation behind this is relational development or relational maintenance (Barta, 2019), in other words, the sharing of private information to facilitate relational closeness, increasing a sense of intimacy in a relationship (Altman \& Taylor, 1973). 
ONLINE DISCLOSURE OF SEXUAL VICTIMISATION

Commercial goals. Finally, one study found that victims sometimes have commercial aspirations with sharing stories of sexual victimisation. In YouTube videos about rape, victims aimed at promoting certain products or themselves as YouTubers (Harrington, 2019).

\section{Other-orientated Disclosure}

Provide support. In addition to seeking support in an online environment, victims can also choose to disclose their story online to provide support and help other victims. Support can thus be both individual- and other-orientated. One study even explicitly revealed that victims shared their story online to fill the gap of support for other victims (Gundersen \& Zaleski, 2020). This motivation to support other victims emerged in eight studies (Andalibi et al., 2016; Barta, 2019; Dancig-Rosenberg \& Peleg, 2020c; Fileborn, 2017; Fawcett \& Shrestha, 2016; Gundersen \& Zaleski, 2020; Loney-Howes, 2018; Masciantonio et al., 2020).

Educate. A second 'other-benefiting' motivation to disclose experiences of sexual victimisation online is the wish to educate others. In this context, others can mean other victims, as well as others in general. Overarching motivations are the wish for people to learn from their experiences (Harrington, 2019), to educate those who practice victim blaming (Gundersen \& Zaleski, 2020) and to change perceptions and opinions about sexual violence (Masciantonio et al., 2020). This motivation was found in four studies (Barta, 2019; Gundersen \& Zaleski, 2020; Harrington, 2019; Masciantonio et al., 2020).

Activism. The final motivation for online disclosure is activism. Motivations for online disclosure within this theme ranged from sharing the story to highlight the magnitude of the problem (Fileborn, 2017; Masciantonio et al., 2020), warning others and society (DancigRosenberg \& Peleg, 2020c; Fileborn, 2017), raising awareness (Barta, 2019; Gundersen \& Zaleski, 2020), challenging stigma and sexual assault myths (Barta, 2019; Gundersen \& Zaleski, 2020) expressing disapproval and making an activist call for social change (DancigRosenberg \& Peleg, 2020c; Masciantonio et al., 2020). The motivation “activism” was 


\section{ONLINE DISCLOSURE OF SEXUAL VICTIMISATION}

manifested by bringing attention to the problem and ventilating dissatisfaction (Mendes et al., 2019) and was found in eight studies (Barta, 2019; Dancig-Rosenberg \& Peleg, 2020c; Fawcett \& Shrestha, 2016; Fileborn, 2017; Gundersen \& Zaleski, 2020; Loney-Howes, 2018; Masciantonio et al., 2020; Mendes et al., 2019).

In conclusion, victims of sexual violence can have very different motivations to disclose their experiences online. The motivations 'seek support', 'provide support' and 'activism' were most prevalent in the included studies $(N=8)$ as reasons for online disclosure of sexual victimisation, followed by 'clarification and validation' $(N=7)$ and 'documenting' $(N=6)$. Victims often have multiple motivations simultaneously or consecutively (Barta, 2019) and motivations can be both individual- and other-oriented. An important side note is that the relative weight of the different motivations remains unknown. Besides, several motives for disclosure can coexist, but it is unclear which motives go together more often than others.

\section{Motivations for Not Disclosing Online}

Only one study (Masciantonio et al., 2020) also reported on why victims of sexual violence refrained from disclosing their experience. Victims did not tweet about their victimisation because of a distrust of their followers, they did not think of Twitter as a suitable place to talk about private events, they thought it was time to move on, a fear of backlash and because of feelings of shame.

\section{Responses to Online Disclosure of Sexual Victimisation}

Responses to online disclosure of sexual victimisation can be classified using different categorizations. Researchers have used different scales for this. The two most commonly used scales are the Social Support Behavior Code (SSBC) (Cutrona \& Suhr, 1992) and Ullman's (2000) Social Reactions Questionnaire (SRQ). The SSBC consists of five categories of support: informational support (information or advice), instrumental support (physical or monetary assistance), esteem support (promoting one's abilities and value), network support (enhance a 
ONLINE DISCLOSURE OF SEXUAL VICTIMISATION

sense of belonging to a group), and emotional support (empathy, caring or concern). The SRQ (Ullman, 2000) is most widely used to measure the reactions to disclosure of sexual victimisation and combines the categories of instrumental, informational and emotional support from the SSBC with negative social reactions. Three of the included studies used SSBC (Andalibi et al., 2016; Andalibi et al., 2018; Lowenstein-Barkai, 2020), two studies used SRQ (Bogen et al., 2018a; Bogen et al., 2019). Lowenstein-Barkai (2020) used the SSBC but added three categories: retributive support, unsupportive reactions and other. Retributive support contains reactions with calls for punishing the perpetrator and restoration of justice. Unsupportive reactions are responses that blame or criticise the victim, express disbelief, minimise the severity of the victimisation or reactions aimed at provoking controversy (also known as trolling) (Lowenstein-Barkai, 2020).

Ten studies, both qualitative, quantitative and mixed methods, reported on the responses to online disclosure of sexual victimisation (Andalibi et al., 2018; Bogen et al., 2018a; Bogen et al., 2019; Dancig-Rosenberg \& Peleg, 2020a; Lowenstein-Barkai, 2020; Moors \& Webber, 2012; Schneider \& Carpenter, 2020; Webber, 2014; Webber \& Moors, 2015; Webber \& Wilmot, 2012). In general, responses to these online messages seem predominantly positive (Andalibi et al., 2018; Bogen et al., 2018a; Bogen et al., 2019; Lowenstein-Barkai, 2020; Moors \& Webber, 2012; Webber \& Wilmot, 2012). The most prevalent types of positive responses were comments containing advocacy (Bogen et al., 2018a; Bogen et al., 2019; Schneider \& Carpenter, 2020), emotional (Andalibi et al., 2018; Lowenstein-Barkai, 2020; Schneider \& Carpenter, 2020) and informational support (Andalibi et al., 2018). Using quantitative content analysis of responses to online disclosures, Lowenstein-Barkai (2020) found a sex difference between the kind of support men and women received after disclosing their victimisation. Women receive more emotional and network support, while men receive more responses containing retributive support. The proportion of positive reactions of all responses varied 
ONLINE DISCLOSURE OF SEXUAL VICTIMISATION

between $61 \%$ in a qualitative content analysis (Bogen et al., 2018a) and 99\% in a quantitative content analysis (Lowenstein-Barkai, 2020).

Online disclosures of sexual victimisation also received negative responses. The most common negative responses to online disclosure of sexual victimisation were egocentric and distracting responses (Bogen et al., 2018a; Bogen, 2019; Schneider \& Carpenter, 2020). Egocentric responses focus more on the reader's emotional response than on the victim. Distracting comments directed the attention away from the victims (Ullman, 2000). However, it is unclear to what extent these responses are considered negative. Where distracting reactions can be viewed as negatively drawing attention away from the victims' experience, several researchers have argued that, depending on the context, these responses may be perceived as helpful (Campbell, Wasco, Ahrens, Self \& Barnes, 2001; Dworkin, Newton, \& Allen, 2018). Despite the fact that politically-oriented tweets did not directly support victims, the tweets did condemn the perpetrators. Dancig-Rosenberg and Peleg (2020a) also found that victims received insulting and victim blaming responses to their online disclosure. An important side note is that in some studies the platforms that were researched moderated the content in some form, meaning that negative comments might have been removed before data collection or that these were screened and filtered out before publication (Andalibi et al., 2018; Barta, 2019; Moors \& Webber, 2012; Webber \& Wilmot, 2012). The proportion of negative responses ranged from 1\% (Lowenstein-Barkai, 2020) to 33\% (Bogen et al., 2019).

Finally, in addition to positive and negative responses to online disclosure, victims also received reactions with reciprocal disclosures (Andalibi et al., 2018; Webber \& Wilmot, 2012). Andalibi and colleagues (2018) found this in almost 30\% of cases.

Webber (2014), Webber and Moors (2015) and Webber and Wilmot (2012) studied the responses of professional counsellors and other members of 'Yahoo! Answers' (Webber, 2014; Webber \& Moors, 2015) or 'Somazone' (Webber \& Wilmot, 2012) to online disclosure of 


\section{ONLINE DISCLOSURE OF SEXUAL VICTIMISATION}

sexual victimisation. All three studies found that counsellors often provided affirmation, support in interpreting or reflecting on the experience, advice (personal, medical and legal) and offered other resources of help (Webber, 2014; Webber \& Wilmot, 2012; Moors \& Webber, 2012). Counsellors' responses were often supportive, non-judgmental (Webber, 2014; Webber \& Moors, 2015; Webber \& Wilmot, 2012), systematic, consistent and detailed (Webber \& Moors, 2015). Comments by other users were often positive and supportive (Webber, 2014; Webber \& Moors, 2015; Webber \& Wilmot, 2012) and used emotionally charged language and humour (Webber \& Wilmot, 2012). Responses by readers lacked consistency and appropriate advice, empathy or resources (Webber, 2014).

\section{Effect Online Disclosure and Responses to Online Disclosure}

Little information is available about the effect of online disclosure of sexual victimisation as well as the effect of responses to online disclosure. Statements about these effects can be made based on only four studies (Barta, 2019; Dancig-Rosenberg \& Peleg, 2020a, 2020b; Gundersen \& Zaleski, 2020; Loney-Howes, 2018). These studies used qualitative or mixed methods.

First, the impact of online disclosure on the victims themselves. Gundersen and Zaleski (2020) interviewed 20 victims of sexual violence and concluded that they had undergone an identity shift, both personally and professionally. Victims indicated that they experienced relief of mental health problems and a decrease in shame and self-blame. Another study, which also included interviews, revealed that victims who had online disclosed sexual victimisation had a dispel in the sense of loneliness, a connect with other victims and that disclosure had helped to develop a support network (Dancig-Rosenberg \& Peleg, 2020a). Loney-Howes (2018) and Barta (2019) also found that online disclosure contributed to personal healing and coping.

On the other hand, the study by Dancig-Rosenberg and Peleg (2020a) also found negative effects. They found that there is a high emotional price for the victims caused by media exposure. Some of the interviewed victims suffered from social rejection or personal fatigue 


\section{ONLINE DISCLOSURE OF SEXUAL VICTIMISATION}

from their public exposure as a victim and exhaustion as a result of the intensity of the triggering \#MeToo movement.

The effect of the responses to online disclosure, according to Barta (2019), varied depending on the expectations, the relationship with the commenter, where the response was given and the nature of the response. Positive responses helped reduce barriers and shame to disclose and ensured victims felt heard, supported and validated (Gundersen \& Zaleski, 2020; Loney-Howes, 2018). Regarding the relationship with the commenter, Barta (2019) found that negative reactions from strangers had less impact on the victim than negative reactions from friends or family. In addition to negative reactions, respondents mentioned the lack of reactions also had an effect. Some victims stated that the absence of responses lead to a disincentive to further disclose. In contrast, validating responses motivated victims to continue sharing (Barta, 2019).

\section{Discussion}

This systematic literature review provides insight into the content, motivations for and effects of, and responses to online disclosure of sexual victimisation (used as an umbrella term) and offers a first comprehensive insight into the available empirical information on online disclosure of sexual victimisation of studies from a wide variety of research areas. International literature has so far paid limited attention to the various components of online disclosure like characteristics of disclosers (who), characteristics of disclosure messages (what, how, when, where), motivations to disclose (why) and the effects of, and responses to online disclosure of sexual victimisation. The review shows that results of the included studies are often dissimilar or even contradictory. This is likely due to the exploratory nature of the studies, method differences and the diversity of the objects of analysis (amongst which studied platform, hashtag, population). The limitations of the included studies and implications for future research will be discussed more extensively below. 
ONLINE DISCLOSURE OF SEXUAL VICTIMISATION

\section{Limitations and Implications for Future Research}

A first methodological limitation is that a theoretical basis and well-defined research questions were often lacking. It may be that this is due to the fact that existing victimological theory is insufficient, or authors are insufficiently experienced in identifying and applying theory. Based on this review, it can be stated that victims of sexual violence who disclose their victimisation online appear to have needs that are potentially not met in the offline world. In several studies victims described 'having nowhere else to turn to' and dissatisfaction with offline disclosure as explanations for disclosing online (Andalibi et al., 2016; Barta, 2019; Dancig-Rosenberg \& Peleg, 2020a; Fawcett \& Shrestha, 2016; Fornari et al., 2018; Moors \& Webber, 2012; O’Neill, 2018). However, experiences with offline disclosure or needs of victims after sexual violence were not measured in the included studies so the link with online disclosure is rather speculative. It is conceivable that the internet offers unique features (such as anonymity and invisibility) and an online disinhibition effect (Suler, 2004) to meet the needs of victims. Further research into this relationship is necessary.

A second limitation of the included studies relates to research design. For example, the results of the majority of studies about the motivations for online disclosure were based on content analysis, implying that answers were based on the content of the online messages only. Four studies asked victims themselves about their motivations for online disclosure. However, the sample sizes of the interviews were low $(N=8$ to $N=27)$ and in three out of four studies interviews were conducted by telephone or via Skype. Telephone interviews have several limitations like absence of nonverbal communication and complications in building trust and a safe environment to disclose (Barta, 2019). ${ }^{3}$ Also, only one study compared the motives of those who shared their victimisation online with victims who had chosen not to do so, but focused on Twitter only and had a small sample size. It is thus virtually impossible to identify motivations for online disclosure of sexual victimisation with the used research methods.

Studies were largely qualitative, explorative or descriptive in nature and used 


\section{ONLINE DISCLOSURE OF SEXUAL VICTIMISATION}

convenience or purposive sampling. For the content analysis, many studies used the Twitter API, which is free and public but provides only a portion of the available content, so the data are incomplete. Which content was scraped was uncertain, so how and in what way the data are incomplete remains unclear (Barta, 2019). The use of the paid premium Twitter API is also not without problems (see Modrek \& Chakalov, 2019). Two studies used a paid commercial tool to collect the social media data of which again the algorithm is opaque. In other words, data collection using the Twitter API has a selection bias, but how the data are biased is unknown. The differences and contradictions between the results of the included studies may therefore also reflect different selection biases. Additionally, the included studies conducted research on different platforms, with different characteristics, users and goals, in different time periods, adding to the incomparability of the content of, motivations for, and responses to online disclosure of sexual victimisation. As an example, asking a question on a website like 'Yahoo! Answers', 'Somazone' or in a semi-private forum like '/r/rapecounseling' on Reddit is potentially incomparable to disclosure of sexual victimisation on public social media platforms like YouTube, Twitter or Facebook. Furthermore, online disclosure in private groups and on Instagram, one of the most popular social media platforms (more than twice as much as Reddit and almost three times the number of users of Twitter) (Clement, 2020) was not studied. The content and motivation of such messages may differ from public messages or other social media platforms. Future research into online disclosure of sexual victimisation should make use of more transparent methods of data collection, avoid the use of opaque social media APIs, focus on as yet understudied platforms for online disclosure and compare the group of victims who online disclose their experiences to those who refrain from doing so.

A third limitation regards operationalisation. The used constructs and measures (for example "emotions") in the included studies were rarely defined. This left the authors no choice but to lump together all studies and types of sexual victimisation. From the given 
ONLINE DISCLOSURE OF SEXUAL VICTIMISATION

conceptualisations it was, however, clear that not all researchers operationalised 'sexual violence' the same way. Fileborn (2017) for example studied street harassment as a form of sexual violence. However, not all types of street harassment are necessarily a form of sexual violence, and it is important to recognise the ways in which it manifests as other types of violence and abuse (e.g., racist, homophobic, transphobic and so forth) (B. Fileborn, personal communication, March 25, 2020). Lumping different types of sexual victimisation together in an attempt to capture a broad spectrum of experiences makes it impossible to differentiate between criminal and unwanted, though still harmful, behaviour. A distinction that is often made in social, but especially in a legal context.

The same goes for the operationalisation of a disclosure. Only a handful of studies differentiated between direct and indirect disclosures and clearly defined which posts were and which posts were not classified as a disclosure. The relationship between what (type of sexual victimisation), why (motivations) and how (characteristics of disclosures) sexual victimisation was disclosed and the responses to the disclosures could therefore often not be determined. Next to the fact that results may not be representative of all victims who disclose their story online, or cannot be generalised to other platforms or all victims of sexual violence, knowledge of online disclosure is further limited by the criteria used to define disclosure and sexual violence.

Fourth, only a handful of studies (e.g. Mendes et al., 2019) explicitly studied images (such as pictures, video content or emoticons) accompanying written online disclosures. The analysis of for example video content (as performed by Harrington, 2019) differs from the analysis of written text because of the different and possible multi-interpretable nature of nonverbal communication such as expressed emotions, intonation, pauses, posture and facial expressions of the respondent. The same goes for the use of pictures or images, sequences of emoticons and the use of interpunction. With the increased use of pictures and videos online, 
ONLINE DISCLOSURE OF SEXUAL VICTIMISATION

future research should also explicitly incorporate such expressions in analysis.

Fifth, a large part of the studies focused on specific hashtags or highly visible online movements such as the \#MeToo. This is problematic because these hashtags are often driven by activist principles, with a call to use the hashtag to raise awareness. It cannot be determined objectively whether the individuals who disclosed were motivated by an online movement to share their story and whether they would have shared their story if they had not been motivated by others. Although this also applies to the disclosure of sexual violence outside of viral movements, it is to be expected that highly visible hashtags that get a lot of (media) attention are more likely to encourage others to disclose their own experiences than messages outside such movements (Barta, 2019). It is also unclear whether participating in a social media movement influenced the content of the disclosures and the responses they elicited. Focusing on online disclosures of sexual victimisation during viral movements may distort the identified motivations to disclose. In other words, viral hashtags may be driven by other-oriented motivations rather than individuals seeking help, advice or support for their own recovery and might therefore concern a specific subsample of disclosures (Barta, 2019). Future research should attempt to capture a broader range of more 'ordinary' online messages, outside of viral movements, containing disclosure of sexual victimisation in order to make more broadly relevant statements.

A sixth and final caution is that the majority of the included studies came from Englishspeaking countries and focus on English online disclosure posts. In this systematic review we aimed at including as diverse an overview as possible of research and literature on the phenomenon of online disclosure of sexual victimisation. The review included not only peer reviewed studies but also a dissertation, a preprint and a publication in proceedings of a conference. Despite this explicit effort, mostly research from the Anglosphere (mainly Australia, the US and the UK) was found. Only a few studies from Asia (Israel), South America 


\section{ONLINE DISCLOSURE OF SEXUAL VICTIMISATION}

(Brazil) and Europe (Ukraine and France) were found. It is unclear how the results with a lack of global diversity, centred on Global North perspectives, translate to other countries and cultures. It is recommended that future research focuses on online disclosure of sexual victimisation in other contexts so that international and intercultural comparisons can be made. This should be studied while considering the characteristics of the national and cultural differences of the feminist movement and the differential impact that the \#MeToo campaign may have had on the general public and the victims.

\section{Conclusion}

Despite the (methodological) shortcomings of the included studies, some conclusions can be drawn from this review. Information about the characteristics of victims who share their sexual victimisation online and for whom is scarce. Significant variation was found across studies in the sense that some studies reported that victims of sexual violence online disclose their experiences in detail, while other studies state that victims rarely label the incident and disclose implicitly or in abstract terms. Overall, disclosures generally focus on the psychological, emotional and social impact of the sexual victimisation. The tone of the online disclosure of sexual victimisation is often emotional, with shame being the prevailing emotion. This might be, though speculative, indicative of online disinhibition (Suler, 2004; Joinson, 1998), where victims feel open to express emotions and be less worried about how they present themselves. Sexual victimisation is mostly shared after reaching a point in recovery in which victims feel confident enough to talk about it (Barta, 2019).

Across studies, victims of sexual violence have different motivations to share their experiences online. These motivations can be individual-oriented (to seek support, clarification and validation, unburdening, documenting, seeking justice, informing others or commercial goals) and other-oriented (provide support, educate, activism). The motivations 'seek support', 
ONLINE DISCLOSURE OF SEXUAL VICTIMISATION

'provide support' and 'activism' were most prevalent.

Responses to online disclosure are predominantly positive and contain advocacy, emotional and informational support. Few negative responses were found, with the prevailing negative responses being egocentric and distracting responses. The proposed disinhibition due to the absence of expectations to respond to sexual victimisation disclosures in a socially desirable manner (Suler, 2004; Joinson, 1998) did not seem to result in large numbers of negative responses.

The effects of online disclosure and of responses to online disclosure remain largely unknown. Reported positive effects were a relief of mental health problems and decrease of shame and self-blame, similar to effects found after offline disclosure of sexual victimisation (Pennebaker, Zech \& Rime, 2001; Rime, 1995), but these should be interpreted with caution considering the indications of the timing of disclosure (after recovery and when feeling strong enough). Negative effects were social isolation and personal fatigue.

The review showed that seeking help, support and advice are important motivations to online disclose sexual victimisation. This, in combination with a large proportion of the victims who have never shared their victimisation before or who have had bad experiences with offline disclosure, offers important points of intervention for assistance and victim support. Online informal support might be beneficial and could serve as an alternative to offline disclosure in cases of geographical isolation, fear of face-to-face contact, limited access to help or privacy barriers (Webber \& Wilmot, 2012). Sharing in an online environment together with feedback found to be predominantly positive can be a way to explore disclosing in a relatively safe manner. Burrows (2011) calls for training of social workers in recommending and facilitating the use of online support forums for victims of sexual violence. This review confirms the potential for this suggestion.

Given the likely increasing importance of the internet and social media for sharing 


\section{ONLINE DISCLOSURE OF SEXUAL VICTIMISATION}

personal information and experiences, such as sexual victimisation, it is important that more research is conducted on this phenomenon. This future research would ideally supersede the identified weaknesses and gaps in the existing literature.

\begin{tabular}{|c|c|}
\hline \multicolumn{2}{|c|}{ Summary findings } \\
\hline Included studies & $\begin{array}{l}\text { Mostly recent research with the highest number of } \\
\text { publications in } 2018 \text {, followed by } 2019 .\end{array}$ \\
\hline Methodology & $\begin{array}{l}\text { - Included studies largely qualitative, explorative } \\
\text { and descriptive, using small and non- } \\
\text { representative samples. } \\
\text { - Majority of the studies conducted a qualitative } \\
\text { content analysis of a specific hashtag. } \\
\text { - Large method differences (key constructs, } \\
\text { platform, time period, design) complicate } \\
\text { synthesis of findings. }\end{array}$ \\
\hline Characteristics of disclosers & $\begin{array}{l}\text { Information on disclosers largely unexplored. White } \\
\text { women aged } 25 \text { to } 50 \text { years old overrepresented. }\end{array}$ \\
\hline $\begin{array}{l}\text { Characteristics of disclosure } \\
\text { messages }\end{array}$ & $\begin{array}{l}\text { Varied content and degree of detail: from } \\
\text { detailed descriptions to abstract terms, a broad } \\
\text { range of emotions (e.g. shame, sadness, fear). } \\
\text { - Disclosures often contained a description of the } \\
\text { aftermath and social and psychological effects of } \\
\text { sexual victimisation. }\end{array}$ \\
\hline Motivations for online disclosure & $\begin{array}{l}\text { Differing motivations for online disclosure, both } \\
\text { individual-oriented (to seek support, clarification } \\
\text { and validation, unburdening, documenting, seeking } \\
\text { justice, informing others or commercial goals) and } \\
\text { other-oriented (provide support, educate, activism). } \\
\text { The motivations 'seek support', 'provide support' } \\
\text { and 'activism' most prevalent. }\end{array}$ \\
\hline Responses to online disclosure & $\begin{array}{l}\text { Responses to online disclosure predominantly } \\
\text { positive and contain advocacy, emotional and } \\
\text { informational support. The few negative responses } \\
\text { were mainly egocentric and distracting. }\end{array}$ \\
\hline $\begin{array}{l}\text { Effect online disclosure and } \\
\text { responses }\end{array}$ & $\begin{array}{l}\text { Effects of online disclosure and of responses to } \\
\text { online disclosure largely unknown. Reported } \\
\text { positive effects were a relief of mental health } \\
\text { problems and decrease of shame and self-blame. } \\
\text { Negative effects were social isolation and personal } \\
\text { fatigue. }\end{array}$ \\
\hline \multicolumn{2}{|r|}{ Implications } \\
\hline \multicolumn{2}{|c|}{$\begin{array}{l}\text { Future research is needed that uses robust quantitative and/or qualitative designs with } \\
\text { substantial and representative (across platforms) samples, comparing victims who do disclose } \\
\text { their sexual victimisation online with victims who do not, and that compare disclosure on } \\
\text { different online platforms, also outside viral hashtags or movements, to increase } \\
\text { generalisability of the results. }\end{array}$} \\
\hline
\end{tabular}


Implications for practice

Seeking help, support and advice are important motivations to disclose sexual victimisation online. The systematic review identifies the potential for online informal support, in which online disclosure can serve as a relatively safe alternative to offline disclosure. This offers important points of intervention for assistance and victim support by social workers in facilitating the use of the internet for support for victims of sexual violence.

\section{Notes}

1. Throughout this article the terms perpetrator and victim are used as synonyms for the words offender, transgressor and aggressor respectively survivor.

2. The Dutch keywords disclos*, onthul*, 'zelf rapportage*' were combined with keywords related to sexual victimisation ('seks* geweld*', 'seks* misbruik*', 'seks* slachtoffer*', 'seks* intimidat*') and keywords related to the internet ('internet', 'social media', 'online', 'cyber'). The search was expanded with the search terms '(informe*) gerechtigheid', 'activism*', 'protest' combined with the keywords related to sexual victimisation and the keywords related to the internet. Some keywords are the same in Dutch as in English and have therefore not been searched again.

3. In interviews about sensitive topics like sexual violence nonverbal cues offer important information. Tears in someone's eyes, crossing arms, opening the mouth as a sign of the inclination to speak etcetera are all potential signs of (dis)comfort that are invisible in telephone interviews (Barta, 2019). Abrahams (2017) states that in the context of genderbased violence these nonverbal cues are vital in expressing empathy and exert in active listening to victims.

\section{References}

References marked with an asterisk (*) indicate studies included in the systematic review.

Abrahams, H. (2017). Listen to me: a reflection on practice in qualitative interviewing. Journal of Gender-Based $\quad$ Violence, $\quad 1(2), \quad 253-259$. https://doi.org/10.1332/239868017X15090095938377 


\section{ONLINE DISCLOSURE OF SEXUAL VICTIMISATION}

Ahrens, C. E., Campbell, R., Ternier-Thames, N. K., Wasco, S. M., \& Sefl, T. (2007). Deciding whom to tell: Expectations and outcomes of rape survivors' first disclosures. Psychology of Women Quarterly, 31(1), 38-49. https://doi.org/10.1111/j.14716402.2007.00329.x

Ahrens, C. E., Rios-Mandel, L. C., Isas, L., \& del Carmen Lopez, M. (2010). Talking about interpersonal violence: cultural influences on Latinas' identification and disclosure of sexual assault and intimate partner violence. Psychological Trauma, 2(4), 284-295. https://doi.org/10.1037/a0018605

Altman, I., \& Taylor, D. A. (1973). Social penetration: The development of interpersonal relationships. New York: Holt, Rinehart, \& Winston.

*Andalibi, N., Haimson, O. L., De Choudury, M., \& Forte, A. (2016). Understanding social media disclosures of sexual abuse through the lenses of support seeking and anonymity. CHI'16, May 07 - 12, 2016, San Jose, CA, USA, 3906-3918. https://doi.org/10.1145/2858036.2858096

*Andalibi, N., Haimson, O. L., De Choudury, M., \& Forte, A. (2018). Social support, reciprocity, and anonymity in responses to sexual abuse disclosures on social media. ACM Transactions on Computer-Human Interaction, 25(5), 1-35. https://doi.org/10.1145/3234942

*Barta, K. (2019). Reclaiming publicness in the face of sexual assault: Social media, disclosure, and visibility (Dissertation). Retrieved on March 10, 2020 from http://hdl.handle.net/1773/45159

Bhuptani, P. H., \& Messman-Moore, T. L. (2019). Blame and shame in sexual assault. In W. T. O’Donohue \& P. A. Schewe (Eds.), Handbook of Sexual Assault and Sexual Assault Prevention (pp. 309-322). Cham, Switzerland: Springer. https://doi.org/10.1007/978-3-030-23645-8_18 


\section{ONLINE DISCLOSURE OF SEXUAL VICTIMISATION}

*Bogen, K. W., Bleiweiss, K. K., \& Orchowski, L. M. (2018a). Sexual violence is \#NotOkay: Social reactions to disclosures of sexual victimisation on Twitter. Psychology of Violence, 9(1), 127-137. https://doi.org/10.1037/vio0000192

*Bogen, K. W., Bleiweiss, K. K., Leach, N. R., \& Orchowski, L. M. (2019). \#MeToo: Disclosure and response to sexual victimisation on Twitter. Journal of Interpersonal Violence, O0(0), 1-32. https://doi.org/10.1177/0886260519851211

*Bogen, K. W., Millman, C., Huntington, F., \& Orchowski, L. M. (2018b). A qualitative analysis of disclosing sexual victimisation by \#NotOkay during the 2016 presidential election. Violence and Gender, 5(3), 174-181. https://doi.org/10.1089/vio.2017.0053

Burt, M. R. (1980). Cultural myths and support for rape. Journal of Personality and Social Psychology, 38(2), 217-230. https://doi.org/10.1037/0022-3514.38.2.217

Campbell, R., Wasco, S. M., Ahrens, C. E., Sefl, T., \& Barnes, H. E. (2001). Preventing the "second rape": Rape survivors' experiences with community service providers. Journal of Interpersonal $\quad$ Violence, $\quad 16(12), \quad 1239-1259$. https://doi.org/10.1177/088626001016012002

Carretta, C., Burgess, A., \& DeMarcos, R. (2016). To tell or not to tell. Violence Against Women, 22(13), 1499-1518. https://doi.org/10.1177/ 1077801215590672

Carson, K., Babad, S., Brown, E. J., Brumbaugh, C., Castillo, B., \& Nikulina, V. (2019). Why women are not talking about it: Reasons for nondisclosure of sexual victimisation and associated symptoms of posttraumatic stress disorder and depression. Violence Against Women, 26(3-4), 271-295. https://doi.org/10.1177/1077801219832913

Clement, J. (2020, 14 February). Global social media ranking 2019. Retrieved on March 24, 2020, from https://www.statista.com/statistics/272014/global-social-networks-ranked -by-number-of-users/ 


\section{ONLINE DISCLOSURE OF SEXUAL VICTIMISATION}

Crocker, J., Garcia, J. A., \& Nuer, N. (2008). From egosystem to ecosystem in intergroup interactions: Implications for intergroup reconciliation. In A. Nadler, T. E. Malloy, \& J. D. Fisher (Eds.), The social psychology of intergroup reconciliation (pp. 171-194). New York: Oxford University Press.

Cutrona, C. E., \& Suhr, J. A. (1992). Controllability of stressful events and satisfaction with spouse support behaviors. Communication Research, 19(2), 154-174. https://doi.org/10.1177/009365092019002002

*Dancig-Rosenberg, H., \& Peleg, A. (2020a). Post-trauma and post: Emotion processing of sexual assault victims in criminal proceedings and on Facebook. Law, Society \& Culture (in Hebrew).

*Dancig-Rosenberg, H., \& Peleg, A. (2020b). \#MeToo influences the law?: The sex offender perspective on the impact of the official media and the social media on the law, $\begin{array}{llll}\text { Mishpatim Online (in Hebrew). } & \text { Retrieved }\end{array}$ https://lawjournal.huji.ac.il/article/12/1736

*Dancig-Rosenberg, H., \& Peleg, A. (2020c). Naming, blaming, shaming: Sexual assault victims' perceptions of the practice of shaming their assailants on Facebook, U. HAIFA L. REV. (in Hebrew)

Dworkin, E. R., Menon, S. V., Bystrynski, J., \& Allen, N. E. (2017). Sexual assault victimisation and psychopathology: A review and meta-analysis. Clinical Psychology Review, 56, 65-81. https://doi.org/10.1016/j.cpr.2017.06.002

Dworkin, E. R., Newton, E., \& Allen, N. E. (2018). Seeing roses in the thorn bush: Sexual assault survivors' perceptions of social reactions. Psychology of Violence, 8(1), 100-109. https://doi.org/10.1037/vio0000082

Edwards, K. M., Turchik, J. A., Dardis, C. M., Reynolds, N., \& Gidycz, C. A. (2011). Rape myths: History, individual and institutional-level presence, and implications for change. 
ONLINE DISCLOSURE OF SEXUAL VICTIMISATION

Sex Roles: A Journal of Research, 65, 761-773. https://doi.org/10.1007/s11199-0119943-2

*Fawcett, H. E., \& Shrestha, L. (2016). Blogging about sexual assault: A thematic analysis. The Journal of Forensic Practice, 18(1), 39-51. https://doi.org/10.1108/JFP-05-2015-0032

*Fileborn, B. J. (2017). Justice 2:0: Street harassment victims' use of social media and online activism as sites of informal justice. British Journal of Criminology, 57(6), 1482-1501. https://doi.org/10.1093/bjc/azw093

Fitzgerald, L. F., Magley, V. J., Drasgow, F., \& Waldo, C. R. (1999). Measuring sexual harassment in the military: The sexual experiences questionnaire (SEQ-DOD). Military Psychology, 11(3), 243-263. https://doi.org/10.1207/s15327876mp1103_3

*Fornari L. F., Sakata-So, K. N., Egry, E. Y., \& da Fonseca, R. M. G. S. (2018). Gender and generation perspectives in the narratives of sexually abused women in childhood. Revista Latino Americana de Enfermagem, 26(e3078). https://doi.org/10.1590/15188345.2771 .3078

Freiberg, A., \& Gelb, K. (2008). Penal populism, sentencing councils and sentencing policy. New York: Routledge.

*Gundersen, K. K., \& Zaleski, K. L. (2020): Posting the story of your sexual assault online: A phenomenological study of the aftermath. Feminist Media Studies, 1-13. https://doi.org/10.1080/14680777.2019.1706605

*Harrington, C. (2019). Neo-liberal subjectivity, self-branding and 'My Rape Story' YouTube videos. Critical Sociology, $\quad$ 45(7-8), $\quad$ 1181-1194. https://doi.org/10.1177/0896920518778107

Hébert, M., Tourigny, M., Cyr, M., McDuff, P., \& Joly, J. (2009). Prevalence of childhood sexual abuse and timing of disclosure in a representative sample of adults from Quebec. 
ONLINE DISCLOSURE OF SEXUAL VICTIMISATION

Canadian Journal of Psychiatry, 54(9), 631-636. https://doi.org/10.1177/070674370905400908

Hillis, K., Paasonen, S., \& Petit, M. (2015). Networked Affect. Cambridge: MIT Press.

Hinduja, S., \& Patchin, J. W. (2008). Personal information of adolescents on the Internet: A quantitative content analysis of MySpace. Journal of Adolescence, 31(1), 125-146. https://doi.org/10.1016/j.adolescence.2007.05.004

Jacques-Tiura, A. J., Tkatch, R., Abbey, A., \& Wegner, R. (2010). Disclosure of sexual assault: Characteristics and implications for posttraumatic stress symptoms among African American and Caucasian survivors. Journal of Trauma \& Dissociation, 11(2), 174-192. https://doi.org/10.1080/15299730903502938

Joinson, A. N. (1998). Causes and effects of disinhibition on the Internet. In J. Gackenbach (Ed.) The psychology of the Internet (pp. 43-60). New York: Academic Press.

Kennedy, A. C., \& Prock, K. A. (2018). "I still feel like I am not normal”: A review of the role of stigma and stigmatization among female survivors of child sexual abuse, sexual assault, and intimate partner violence. Trauma, Violence \& Abuse, 19(5), 512-527. https://doi.org/10.1177/1524838016673601

*Lokot, T. (2018). \#IAmNotAfraidToSayIt: stories of sexual violence as everyday political speech on Facebook. Information, Communication \& Society, 21(6), 802-817. https://doi.org/10.1080/1369118X.2018.1430161

London, K., Bruck, M., Wright, D. B., \& Ceci, S. J. (2008). Review of the contemporary literature on how children report sexual abuse to others: Findings, methodological issues, and implications for forensic interviewers. Memory, 16(1), 29-47. https://doi.org/10.1080/09658210701725732 
ONLINE DISCLOSURE OF SEXUAL VICTIMISATION

*Loney-Howes, R. (2018). Shifting the rape script: "Coming out" online as a rape victim. Frontiers: A Journal of Women Studies, 39(2), 26-57. https://doi.org/10.5250/fronjwomestud.39.2.0026

*Lowenstein-Barkai, H. (2020). \#Me(n)Too? Online social support toward male and female survivors of sexual victimisation. Journal of Interpersonal Violence, 00(0), 1-23. https://doi.org/10.1177/0886260520905095

Magley, V. J. (2002). Coping with sexual harassment: Reconceptualizing women's resistance. Journal of Personality and Social Psychology, 83(4), 930-946. https://doi.org/10.1037/0022-3514.83.4.930

*Masciantonio, A., Schumann, S., \& Bourguignon, D. (2020). Sexual and gender-based violence: To tweet or not to tweet? Retrieved on March 10, 2020 from: https://hal.univ-lorraine.fr/hal-02502330/document

*Mendes, K., Keller, J., \& Ringrose, J. (2019). Digitized narratives of sexual violence: Making sexual violence felt and known through digital disclosures. New Media \& Society, 21(6), 1290-1310. https://doi.org/10.1177/1461444818820069

*Modrek, S., \& Chakalov, B. (2019). The \#MeToo movement in the United States: Text analysis of early Twitter conversations. Journal of Medical Internet Research, 21(9). https://doi.org/10.2196/13837

*Moors, R., \& Webber, R. (2012). The dance of disclosure: Online self-disclosure of sexual assault. Qualitative social work, 12(6), 799-815. https://doi.org/10.1177/1473325012464383

Nagy, V. (2016). Narrative construction of sexual violence and rape online. International Journal of Crime, Justice and Social Democracy, 6(2), 95-108. https://doi.org/10.5204/ijcjsd.v6i2.270 
ONLINE DISCLOSURE OF SEXUAL VICTIMISATION

*O’Neill, T. (2018). 'Today I speak': Exploring how victim-survivors use Reddit. International Journal for Crime, Justice and Social Democracy 7(1), 44-59. https://doi.org/10.5204/ijcjsd.v7i1.402

Orchowski, L. M., \& Gidycz, C. A. (2015). Psychological consequences associated with positive and negative responses to disclosure of sexual assault among college women: A prospective study. Violence Against Women, 21(7), 803-823. https://doi.org/10.1177/1077801215584068

Orchowski, L. M., Untied, A. S., \& Gidycz, C. A. (2013). Social reactions to disclosure of sexual victimisation and adjustment among survivors of sexual assault. Journal of Interpersonal $\quad$ Violence, $\quad 28(10), \quad 2005-2023$. https://doi.org/10.1177/0886260512471085

Pennebaker, J. (1997). Opening up: The healing power of expressing emotions. New York: Guilford.

Pennebaker, J., \& Seagal, J. (1999). Forming a story: The health benefits of narrative. Journal of Clinical Psychology, 55(10), 1243-1245. https://doi.org/10.1002/(SICI)10974679(199910)55:10<1243::AID-JCLP6>3.0.CO;2-N

Pennebaker, J., Zech, E., \& Rime, B. (2001). Disclosing and sharing emotion: Psychological, social, and health consequences. In M. Stroebe, R. Hansson, W. Stroebe, \& H. Schut (Eds.), Handbook of bereavement research: Consequences, coping, and care (pp. 517 -543). Washington, DC: American Psychological Association.

Petronio, S. (2002). Boundaries of Privacy: Dialectics of disclosure. Albany, NY: State University of New York Press.

Powell, A. (2015). Seeking rape justice: Formal and informal responses to sexual violence through technosocial counter-publics. Theoretical Criminology, 19(4), 571-588. https://doi.org/10.1177/1362480615576271 


\section{ONLINE DISCLOSURE OF SEXUAL VICTIMISATION}

Rime, B. (1995). Mental rumination, social sharing, and the recovery from emotional exposure. In J. W. Pennebaker (Ed.), Emotion, disclosure, and health (pp. 271-291). Washington, DC: American Psychological Association.

Sable, M. R., Danis, F., Mauzy, D. L., \& Gallagher, S. K. (2006). Barriers to reporting sexual assault for women and men: Perspectives of college students. Journal of American Health, 55(3), 157-162. https://doi.org/10.3200/JACH.55.3.157-162

*Schneider, K. T., \& Carpenter, N. J. (2020). Sharing \#MeToo on Twitter: Incidents, coping responses, and social reactions. Equality, Diversity and Inclusion: An International Journal, 39(1), 87-100. https://doi.org/10.1108/EDI-09-2018-0161

Shaver, P., Schwartz, J., Kirson, D., \& O’Connor, C. (1987). Emotion knowledge: Further exploration of a prototype approach. Journal of Personality and Social Psychology, 52(6), 1061-1086. https://doi.org/10.1037/0022-3514.52.6.1061

Sinclair, B. B., \& Gold, S. R. (1997). The psychological impact of withholding disclosure of child sexual abuse. Violence and Victims, 12(2), 137-145.

Smith, L. (2010). Does posting in an online community encourage young people to disclose sexual assault or abuse? Retrieved on March 10, 2020 from http://www.secasa.com.au/assets/Documents/does-posting-in-an-online-communityencourage-young-people-to-disclose.pdf

Starzynski, L. L., Ullman, S. E., Filipas, H. H., \& Townsend, S. M. (2005). Correlates of women's sexual assault disclosure to informal and formal support sources. Violence and Victims, 20(4), 417-432. https://doi.org/10.1891/vivi.2005.20.4.417

Sudderth, L. K. (1998). 'It'll come right back at me': The interactional context of discussing rape with others. Violence Against Women, 4(5), 572-594. https://doi.org/10.1177/1077801298004005004 
ONLINE DISCLOSURE OF SEXUAL VICTIMISATION

Suler, J. (2004). The online disinhibition effect. Cyberpsychology and Behavior, 7(3), 321-326. https://doi.org/10.1089/1094931041291295

Thompson, C., Wood, M. \& Rose, E. (2016). Viral justice: Survivor-selfies, internet virality and justice for victims of intimate partner violence. Presented at the British Society of Criminology Conference: Inequalities in a diverse world.

Thompson, M., Sitterle, D., Clay, G., \& Kingree, J. (2007). Reasons for not reporting victimisations to the police: Do they vary for physical and sexual incidents? Journal of American College Health, 55(5), 277-282. https://doi.org/10.3200/JACH.55.5.277-282

Ullman, S. E. (2000). Psychometric characteristics of the Social Reactions Questionnaire: A measure of reactions to sexual assault victims. Psychology of Women Quarterly, 24(3), 257-271. https://doi.org/10.1111/j.1471-6402.2000.tb00208.x

Ullman, S. E. (2011). Is disclosure of sexual traumas helpful? Comparing experimental laboratory versus field study results. Journal of Aggression, Maltreatment, \& Trauma, 20(2), 148-162. https://doi.org/10.1080/10926771.2011.546751

Ullman, S. E., O’Callaghan, E., Shepp, V., \& Harris, C. (2020). Reasons for and experiences of sexual assault nondisclosure in a diverse community sample. Journal of Family Violence, 35, 839-851. https://doi.org/10.1007/s10896-020-00141-9

*Webber, R. (2014). Sexual assault in relationships: Seeking help on a Q\&A website. Australian Social Work, 67(3), 363-376. https://doi.org/10.1080/0312407X.2013.834065

*Webber, R., \& Moors, R. (2015). Engaging in cyberspace: Seeking for help for sexual assault. Child and Family Social Work, 20(1), 40-49. https://doi.org/10.1111/cfs.12052

*Webber, R., \& Wilmot, J. (2012). Somazone report: Social media and help seeking by young people on sexual assault. Retrieved July 16, 2018, from 
ONLINE DISCLOSURE OF SEXUAL VICTIMISATION

http://www.secasa.com.au/assets/Documents/Social-Media-and-Help-Seeking-byYoung-People-on-Sexual-AssaultSomazone-Report2012.pdf

Williams, J. E. (1984). Secondary victimisation: Confronting public attitudes about rape. Victimology, 9(1), 66-81.

Zinzow, H., \& Thompson, M. (2011). Barriers to reporting sexual victimisation: Prevalence and correlates among undergraduate women. Journal of Aggression, Maltreatment \& Trauma, 20(7), 711-725. https://doi.org/10.1080/10926771.2011.613447 